\title{
Polyols Prepared from Ring-Opening Epoxidized Soybean Oil by a Castor Oil-Based Fatty Diol
}

\author{
Jing Zhang, Ji Jun Tang, and Jiao Xia Zhang \\ College of Materials Science \& Engineering, Jiangsu University of Science and Technology, Zhenjiang 212003, China \\ Correspondence should be addressed to Jing Zhang; badbush2003@163.com
}

Received 13 February 2015; Revised 15 March 2015; Accepted 15 March 2015

Academic Editor: Chuanbing Tang

Copyright (C) 2015 Jing Zhang et al. This is an open access article distributed under the Creative Commons Attribution License, which permits unrestricted use, distribution, and reproduction in any medium, provided the original work is properly cited.

\begin{abstract}
Several biorenewable vegetable oil-based polyols with different molecular weights and various hydroxyl functionalities were successfully prepared by ring-opening epoxidized soybean oil with a castor oil-based fatty diol. It was found that several factors, including reaction time, reaction temperature, and molar ratios between epoxidized soybean oil and castor oil diol, affect structures and rheology behaviors of the final polyols. Proton NMR, FT-IR, GPC, and rheometry results revealed that the hydroxyl functionalities, molecular weight, and viscosity of the polyols could be tailored by controlling the above-mentioned factors. Besides, the role of solvents in the epoxy ring-opening process was investigated as well.
\end{abstract}

\section{Introduction}

Environmental concerns and increasing price of crude oil have triggered great interest in developing materials based on biobased and renewable resources, such as cellulose, starch, natural oil, and sugar [1-3]. Vegetable oils are among the most promising ones with excellent properties [4-6]. Polyurethane is a class of polymers with an extremely versatile range of properties and applications [7,8]. Its structure can be tailored with respect to specific requirement by selecting appropriate polyols and isocyanates. In industry, limited types of isocyanates are available. The wide variety of polyols ensures the versatility of the obtained polyurethanes $[9,10]$. Besides petroleum-based polyols, biobased resources such as soybean oil, castor oil, palm oil have been converted to various polyols in preparation of polyurethane with high thermal stability and mechanical properties [11-14].

Vegetable oils are triglyceride with the structure of an ester formed from glycerol and three fatty acids (Figure 1). There are six most common fatty acids as shown in Table 1: two saturated ones, palmitic (C 16:0) and stearic (C 18:0), and four unsaturated ones, oleic (C 18:1), linoleic (C 18:2), linolenic (C 18:3), and ricinoleic (C 18:1 OH). Reactive sites are ester bonds, carbon-carbon double bonds, and hydroxyl groups which exist in some oils [15]. Among various vegetable oils, soybean oil and castor oil are two important ones (Table 2). Soybean oil is abundant and contains more than four double bonds per molecule. Castor oil inherently contains 2.7 hydroxyl groups per molecule. Both oils have been extensively studied for the production of polyurethanes. However, there are few public literatures which investigate the advantages of combining soybean oil and castor oil in preparation of polyols.

Epoxidation/oxirane ring-opening is one common used method to prepare polyols from vegetable oil $[16,17]$. Petrovic et al. have developed PUs with a broad range from soft and rubbery to hard and glassy from various polyols via oxirane ring-opening of epoxidized vegetable oils. They have studied the effects of the type of triglyceride and diisocyanate used, the $\mathrm{NCO} / \mathrm{OH}$ ratio, and the degree of cross-linking on the properties of PU $[18,19]$. However, the ring-opening agents used are small molecular species, such as ethanol, HX (X-Br, $\mathrm{Cl}, \mathrm{CH} 3 \mathrm{O}$, and $\mathrm{H})$.

In this paper, castor oil diol (COD), derived from castor oil, was used to ring-open epoxy groups in epoxidized soybean oil (ESBO). The effect of ring-opening duration, stoichiometry of COD and ESBO, and reaction temperature was investigated in correlation with the obtained polyol structure and functionalities. Proton NMR, FT-IR, GPC, and rheometry were used to characterize the polyols structure. 
<smiles>[R]C(=O)OCC(COC([R])=O)OC([R])=O</smiles>

FIGURE 1: Schematic structure of vegetable oil $\left(\mathrm{R}_{1}, \mathrm{R}_{2}\right.$, and $\mathrm{R}_{3}$-fatty acid).

TABLE 1: Six common fatty acids' composition in vegetable oils.

\begin{tabular}{|c|c|}
\hline Fatty acids & Structure \\
\hline Palmitic (C 16:0) & $\mathrm{HO}_{2} \mathrm{C} \leadsto$ \\
\hline Stearic (C 18:0) & $\mathrm{HO}_{2} \mathrm{C}_{2}$ \\
\hline Oleic (C 18:1) & $\mathrm{HO}_{2} \mathrm{C}$ \\
\hline Linoleic (C 18:2) & $\mathrm{HO}_{2} \mathrm{C} \sim$ \\
\hline $\begin{array}{l}\text { Linolenic } \\
\text { (C 18:3) }\end{array}$ & $\mathrm{HO}_{2} \mathrm{C}_{-}$ \\
\hline $\begin{array}{l}\text { Ricinoleic } \\
\text { (C 18:1 OH) }\end{array}$ & $\mathrm{HO}_{2} \mathrm{C}$ \\
\hline
\end{tabular}

Polyols with different molecular weights, viscosities, and functionalities will be used for polyurethane preparation.

\section{Materials and Procedure}

2.1. Materials. Completely epoxidized soybean oil with approximately 4.5 oxirane rings per triglyceride was purchased from Scientific Polymer. Magnesium sulfate, fluoroboric acid (48\% in water), isopropanol, and ethyl acetate were purchased from Fisher Scientific. Castor oil, tetrahydrofuran (THF) were obtained from Sigma-Aldrich (Milwaukee, WI). Lithium aluminum hydride (LAH) was purchased from Acros (Geel, Belgium). All materials were used as received without further purification.

2.2. Preparation of Castor Oil-Based Fatty Diol. COD was prepared using a reported procedure [20]. Firstly, $100 \mathrm{~mL}$ of THF was added to LAH in a $1000 \mathrm{~mL}$ two-neck round bottom flask at $0^{\circ} \mathrm{C}$. Secondly, castor oil $(100 \mathrm{~g}, 0.11 \mathrm{~mol})$ was dissolved in $600 \mathrm{~mL}$ of THF and then added dropwise to the LAH suspension with mechanical stirring. The reaction was maintained at $0^{\circ} \mathrm{C}$ for $12 \mathrm{~h}$. The reactant mixture was poured into a $2000 \mathrm{~mL}$ bleak with ice water, followed by the addition of $\mathrm{HCl}$, until the solution was clear. After extraction with $300 \mathrm{~mL}$ of ethyl acetate, the organic layer was purified by washing with water, drying over $\mathrm{MgSO}_{4}$, and filtering. Finally, the clear castor oil diol was obtained after removal of the organic solvent using Rotavapor and dried under vacuum. The yield of COD was about $96 \%$, which was calculated by experimental value divided by theoretical value.

2.3. Preparation of Polyols Based on ESBO and COD. The polyols were prepared by the ring-opening reaction between
ESBO and COD $[18,21]$. Firstly, COD, water, isopropanol, and fluoroboric acid were mixed in a flask with a magnetic stirrer maintained at $40^{\circ} \mathrm{C}$. Then, ESBO was added dropwise in the mixture with vigorous stirring. After being mixed fully, the mixture was stirred for several hours at reaction conditions as shown in Figure 2. Finally, ammonia (30\% in water) was added to quench the reaction. For the purification, the final products were extracted by ethyl acetate and washed with distilled water for several times. The organic layer was then dried over $\mathrm{MgSO}_{4}$ and filtered. The clear viscous light yellow polyols were obtained after removal of organic solvent using Rotavapor and vacuum drying. The yields of polyols were around $92 \%$, which were calculated by experimental value divided by theoretical value. In this paper, the effects of reaction time, molar ratios between COD and ESBO, and reaction temperature on final polyols were investigated. The schematic routine and reaction conditions of preparation of polyols are shown in Figure 2.

2.4. Characterization. ${ }^{1} \mathrm{H}-\mathrm{NMR}$ spectroscopic analysis of the monomers and final products was recorded using a Varian spectrometer (Palo Alto, CA) at $300 \mathrm{MHz}$. All measurements were made by using $\mathrm{CDCl}_{3}$ as solvent. The FT-IR spectra of monomers and polyols were recorded on a Nicolet 460 FT-IR spectrometer (Madison, WI). Rheological experiments were conducted in AR2000ex stress-controlled rheometer (TA Instruments) with parallel plate geometry in room temperature. The $\mathrm{OH}$ number of the polyols was determined with the Unilever method. The molecular weight was tested by using a permeation chromatograph equipped with refractive index detector.

\section{Results and Discussion}

3.1. Preparation of COD. ${ }^{1} \mathrm{H}-\mathrm{NMR}$ spectrum of castor oil and COD is shown in Figure 3. In terms of castor oil, the tertiary proton of the $-\mathrm{CH}_{2} \mathrm{CHCH}_{2}$ - backbone (glycerol structure) appears at $\delta 5.2-5.3$, the methylene proton of the $-\mathrm{CH}_{2}-\mathrm{CHCH}_{2}$-backbone appears at $\delta$ 4.1-4.4, and the tertiary hydrogen adjacent to the hydroxyl proton in fatty acid chain appears at $\delta 3.5-3.6$. After the reduction reaction, the peaks at $\delta 5.2-5.3 \mathrm{ppm}$ and 4.1-4.4 ppm disappeared. On the other hand, the peak intensity at $\delta 3.5-3.6 \mathrm{ppm}$ increased, indicating the complete reduction of triglyceride, resulting in the formation of primary hydroxyl groups. It leads to the conclusion that COD was successfully prepared. 


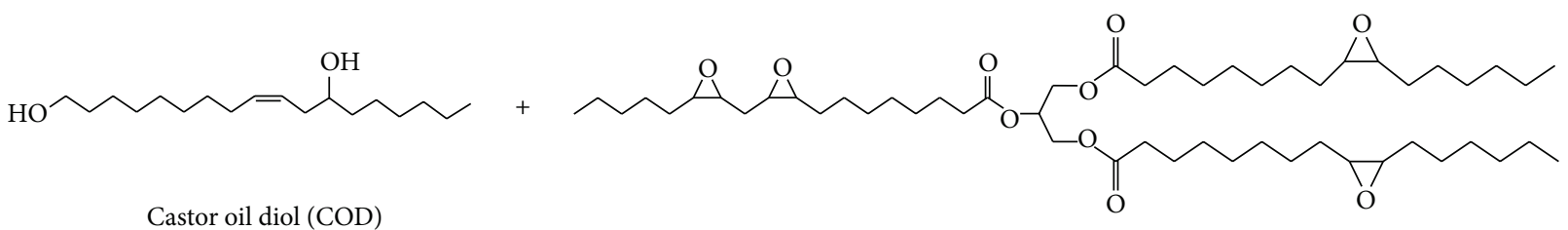

Castor oil diol (COD)

Epoxidized soybean oil (ESBO)

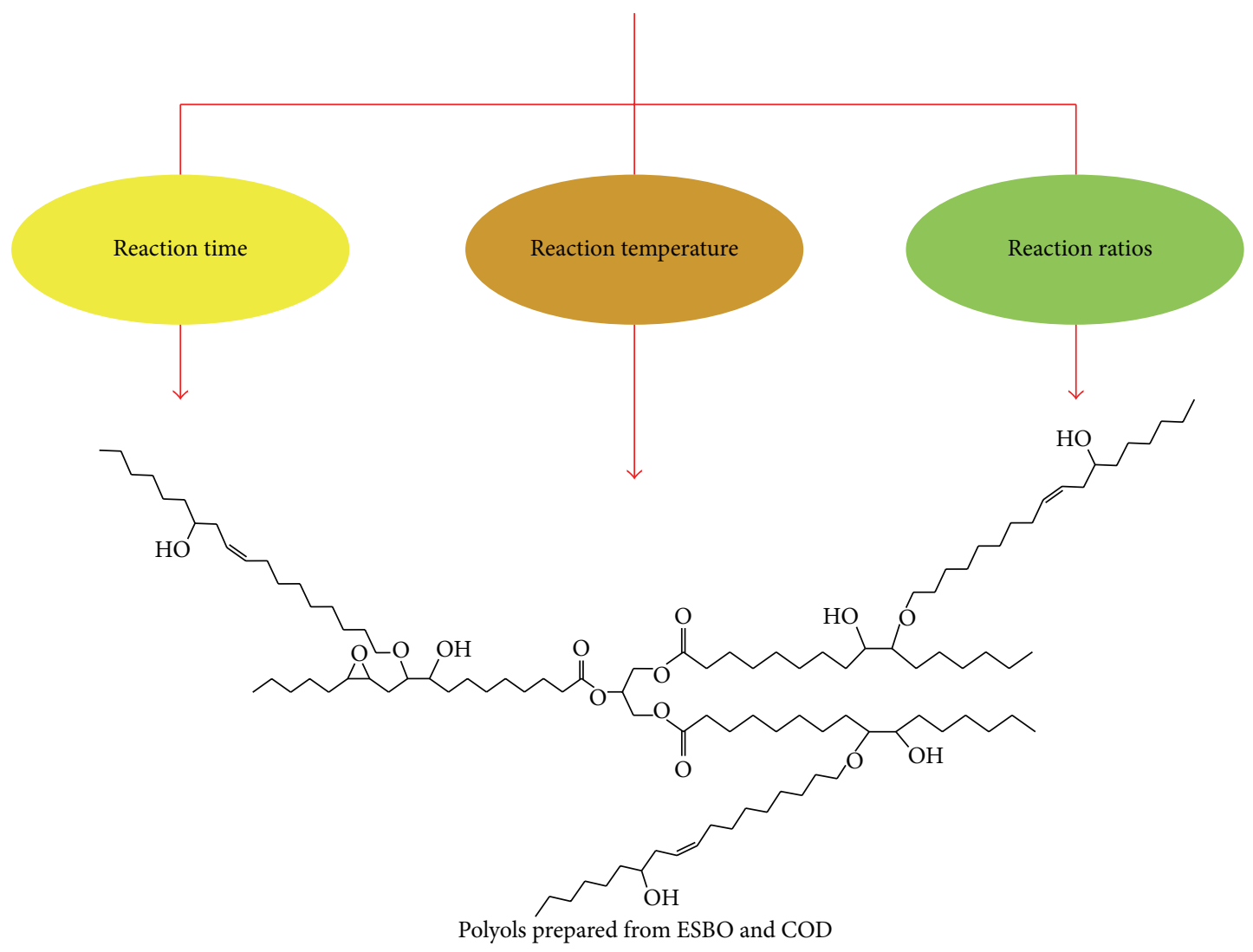

(1) Various reaction time

Reaction time: $15 \mathrm{~min} / 30 \mathrm{~min} / 45 \mathrm{~min} / 1 \mathrm{~h} / 2 \mathrm{~h}$

Reaction ratios: $1.5: 1$

Reaction temperature: $50^{\circ} \mathrm{C}$

(2) Various reaction temperatures

Reaction ratios: $1.5: 1$

Reaction time: $30 \mathrm{~min}$

Reaction temperature: $35^{\circ} \mathrm{C} / 50^{\circ} \mathrm{C} / 65^{\circ} \mathrm{C}$
(3) Various molar ratios

Reaction temperature: $50^{\circ} \mathrm{C}$

Molar ratios between COD and ESBO:

$0.5: 1 ; 1: 1 ; 1.5: 1 ; 2: 1$

Reaction time: $2 \mathrm{~h}$

FIGURE 2: Schematic routine of the preparation of polyols.

3.2. Effect of Reaction Time on the Final Polyols. Figure 4 exhibits ${ }^{1} \mathrm{H}$-NMR spectra of the starting materials and reaction mixture over time during ring-opening. The epoxy group protons appear from 2.8-3.2 ppm in the ${ }^{1} \mathrm{H}-\mathrm{NMR}$ spectra [22]. Besides, the tertiary proton of the $-\mathrm{CH}_{2} \mathrm{CHCH}_{2}$ backbone appears at $\delta 5.2-5.3$, the methylene proton of the $-\mathrm{CH}_{2}-\mathrm{CHCH}_{2}$ - backbone appers at $\delta 4.1-4.4$, and the terminal- $\mathrm{CH}_{3}$ groups appears at $\delta 0.8-1.0$ region $[23,24]$. If the integrated value of area for peaks at 4.1-4.2 ppm $\left(-\mathrm{CH}_{2}-\right.$ $\mathrm{CHCH}_{2}-$ ) is normalized to 2, it is found that the area of peak at 2.8-3.2 ppm in ESBO spectrum is 4.5, indicating the ESBO is completely epoxidized. Plus, it can be observed that epoxy group is noticeably consumed as the reaction time increases. From $1 \mathrm{~h}$ to $2 \mathrm{~h}$, epoxy group number tends to be constant.

Figure 5 shows the FT-IR spectra of ESBO and the polyols prepared from the COD oxirane ring-opening of ESBO with different reaction time. Oxirane absorption at $823 \mathrm{~cm}^{-1}$ disappears after $1 \mathrm{~h}$ (indicated by the dashed vertical line in the enlarged figure). The peak at $3392 \mathrm{~cm}^{-1}$ appears in polyol based ESBO and COD (as shown by the solid horizontal 
TABLE 2: Three classic vegetable oils.

Vegetable oils

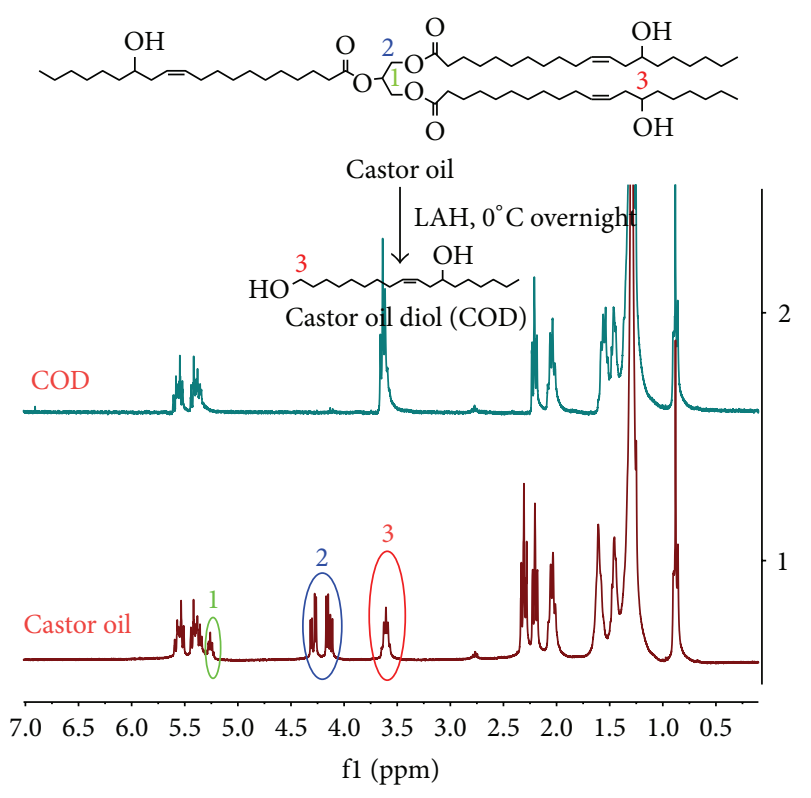

FIgURE $3:{ }^{1} \mathrm{H}-\mathrm{NMR}$ spectrum of castor oil and COD.

line) [23], suggesting that the epoxy groups in ESBO have been ring-opened by COD and hydroxyl groups have been generated.

The GPC plots of polyols with different reaction time of 15 minutes, 30 minutes, 45 minutes, 1 hour, and 2 hours are shown in Figure 6 . The shoulder on the left side of main peak indicates that oligomerization has taken place during the ring-opening reaction. In detail, the oligomerization took place between unreacted epoxies in ESBO and newly formed hydroxyl groups in ESBO, resulting in higher molecular weight. As the reaction proceeds, the molecular weight is expected to increase so that the left shoulder becomes more significant. Due to higher reactivity of the primary hydroxyl groups in COD towards epoxy groups, they are expected to ring-open the oxiranes in ESBO more favorably. When the majority of primary hydroxyls were consumed, the newly

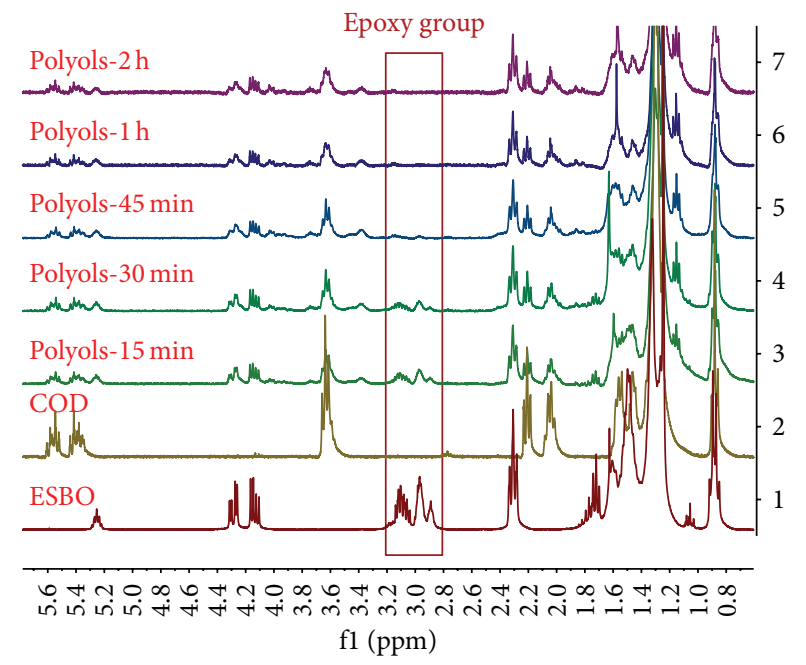

FIGURE $4:{ }^{1} \mathrm{H}-\mathrm{NMR}$ spectrum of polyols with different reaction time.

formed secondary hydroxyls and the secondary hydroxyls in COD contribute to further ring-opening the remaining epoxy groups, resulting in a higher cross-linking. It is worth noting that there is no obvious difference between $45 \mathrm{~min}, 1 \mathrm{~h}$, and $2 \mathrm{~h}$ samples. The molecular weight values are shown in Table 3.

From Figure 4, it is obvious that epoxy groups decrease rapidly in the first $0.25 \mathrm{~h}$ and then continue to decrease gradually until they almost disappear after $1 \mathrm{~h}$. One point that should be mentioned is that there are 4.5 epoxy groups in one ESBO molecule and 1.8 hydroxyl groups in one COD molecule. In this part, the molar ratio of COD and ESBO is $1.5: 1$, indicating that the epoxy group quantity in ESBO is excessive compared to the hydroxyl quantity in COD. Therefore, the following assumption is proposed. Although the epoxy group quantity in ESBO is excessive compared to the hydroxyl quantity in COD, the epoxy groups disappear finally. This has contributed to the hydroxyl groups in solvent and the newly generated hydroxyl groups obtained from 

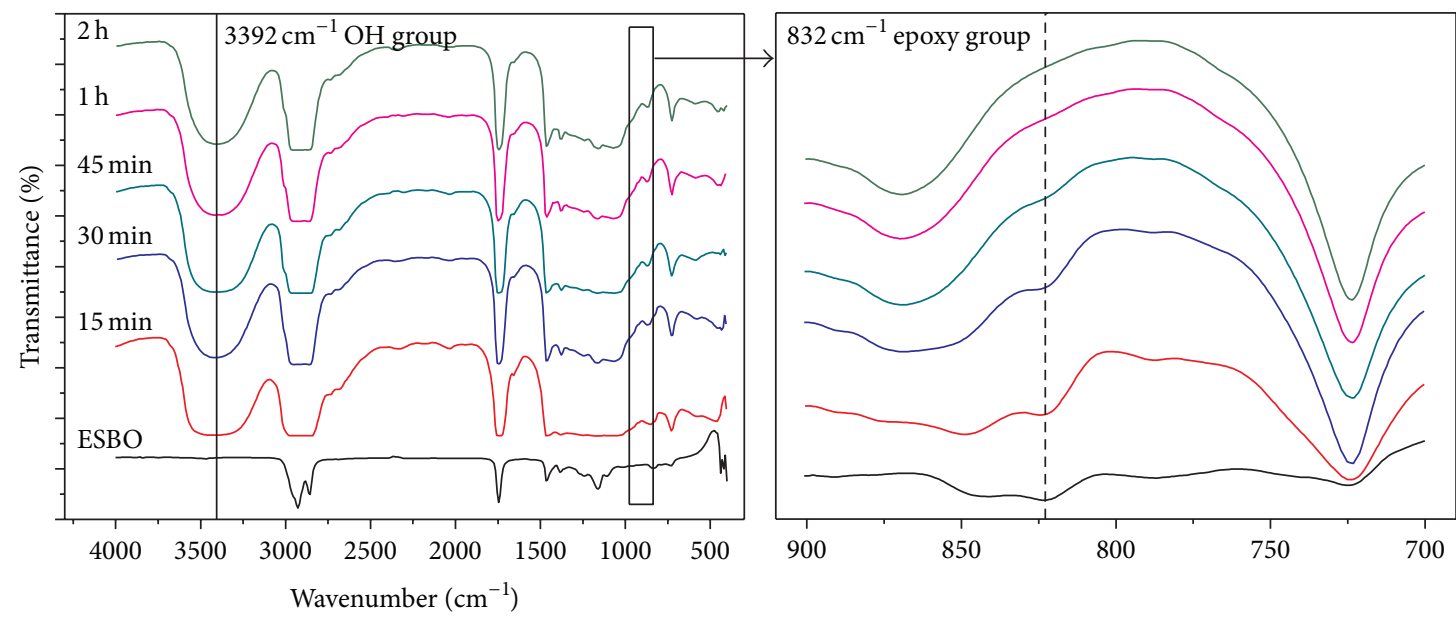

FIgURE 5: FT-IR spectra of ESBO and polyols with different reaction time.

TABLE 3: Polyols prepared from ESBO-COD reaction.

\begin{tabular}{|c|c|c|c|c|c|c|c|}
\hline Polyols & $\begin{array}{c}\text { Reaction } \\
\text { temperature } \\
\left({ }^{\circ} \mathrm{C}\right)\end{array}$ & $\begin{array}{l}\text { Reaction time } \\
\text { (Hour) }\end{array}$ & $\begin{array}{l}\text { Reaction } \\
\text { ratios }\end{array}$ & $\begin{array}{l}\text { Viscosity } \\
\text { (Pa s) }\end{array}$ & $\begin{array}{l}\text { OH number } \\
(\mathrm{mg} \mathrm{KOH} / \mathrm{g})\end{array}$ & $\begin{array}{l}\text { Number/weight } \\
\text { average molecular } \\
\text { weight }\end{array}$ & PDI \\
\hline 1 & 50 & 0.25 & $1.5: 1$ & 0.96 & 194.0 & $1655 / 1730$ & 1.05 \\
\hline 2 & 50 & 0.5 & $1.5: 1$ & 1.42 & 225.5 & $1713 / 1801$ & 1.05 \\
\hline 3 & 50 & 0.75 & $1.5: 1$ & 3.46 & 237.6 & $1835 / 1946$ & 1.06 \\
\hline 4 & 50 & 1 & $1.5: 1$ & 4.50 & 244.4 & $1863 / 1972$ & 1.06 \\
\hline 5 & 50 & 2 & $1.5: 1$ & 5.23 & 243.5 & $1880 / 1993$ & 1.06 \\
\hline 6 & 50 & 2 & $0.5: 1$ & 11.19 & 221.6 & $1872 / 2008$ & 1.07 \\
\hline 7 & 50 & 2 & $1: 1$ & 8.32 & 241.5 & $1775 / 1860$ & 1.05 \\
\hline 8 & 50 & 2 & $2: 1$ & 2.96 & 259.1 & $1865 / 1981$ & 1.06 \\
\hline 9 & 35 & 0.5 & $1.5: 1$ & 0.65 & 210.3 & $1621 / 1687$ & 1.04 \\
\hline 10 & 65 & 0.5 & $1.5: 1$ & 4.06 & 246.4 & $1853 / 1958$ & 1.06 \\
\hline
\end{tabular}

ring-opening of ESBO [25]. The latter factor was confirmed by GPC results. To investigate the solvent's role in ringopening reaction, the reaction was conducted without COD and other reaction factors were maintained. Figure 7 shows that the epoxy group peak at 2.8-3.2 ppm of the obtained polyol disappears, which indicates that the solvent actually participates in the ring-opening reaction.

And, meanwhile, the $\mathrm{OH}$ numbers of the polyols increase until the reaction time reaches $1 \mathrm{~h}$ and then become constant as shown in Figure 8. Theoretically, the $\mathrm{OH}$ numbers of polyols should equal that of COD, because the ring-opening reaction between the hydroxyl group of COD and the epoxy group of ESBO will generate another new hydroxyl group. For the investigation of effect of reaction time, the amount of ESBO and COD remains constant. The increase of $\mathrm{OH}$ numbers of final polyols with increasing reaction time should result from the fact that the solvent used also ring-opens the epoxy groups. The rheological behaviors of polyols with different reaction time are shown in Figure 9. It is found that, with reaction time increases, the products become more viscous and shear thin behavior emerges instead of
Newtonian behavior. The viscosity conforms to the molecular weight obtained by GPC.

3.3. Effect of Reaction Temperature on the Final Polyols. In this part, three reaction temperatures were chosen to investigate their effect on the final polyols' structure and functionalities. Reaction time was set as $30 \mathrm{~min}$, with the purpose of avoiding the complete ring-opening in order to demonstrate the difference of epoxy groups residue amount. From Figure 10, it is found that raising reaction temperatures will lead to the decreasing epoxy group residue. Table 3 illustrates that $\mathrm{OH}$ numbers and viscosity both increase with increasing reaction temperature. It can be concluded that higher temperature accelerates the reaction rate of COD and ESBO.

The GPC plots and molecular weight data of polyols with different reaction temperatures of $35^{\circ} \mathrm{C}, 50^{\circ} \mathrm{C}$, and $65^{\circ} \mathrm{C}$ are shown in Figure 11 and Table 3, respectively, which also lead to the conclusion above.

3.4. Effect of Reaction Ratios between COD and ESBO on the Final Polyols. In the following investigation, reaction time 


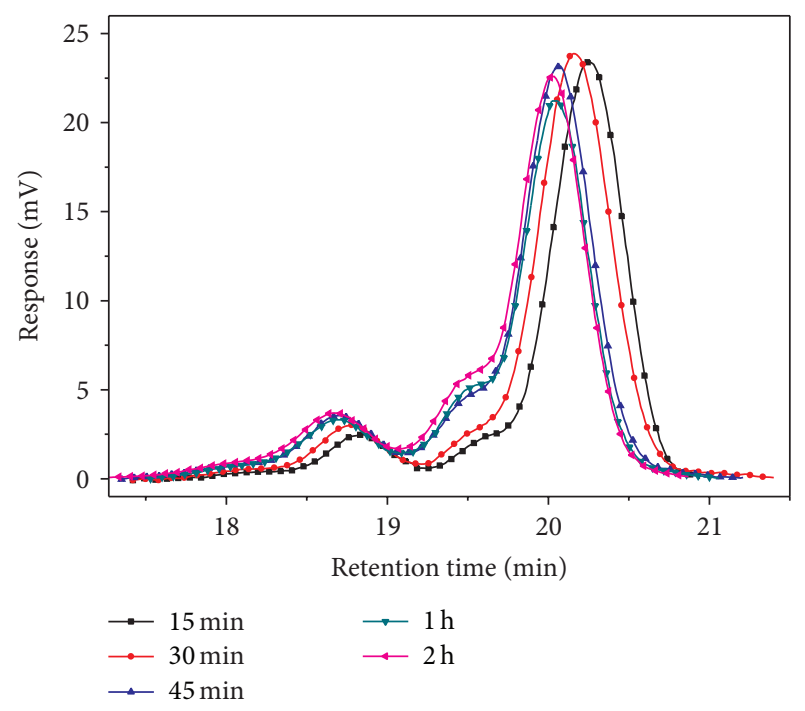

FIGURE 6: GPC plots of polyols with different reaction time.

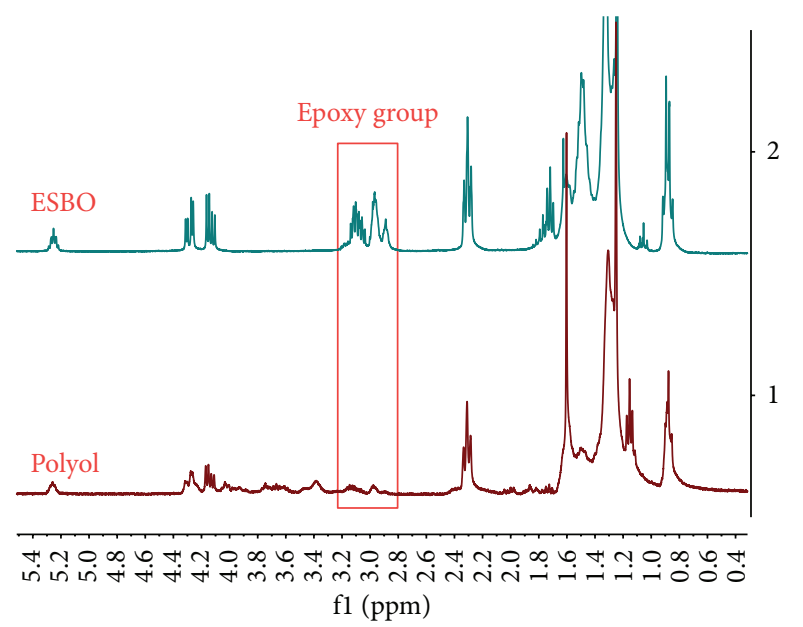

Figure 7: ${ }^{1} \mathrm{H}-\mathrm{NMR}$ spectrum of polyol from ESBO and solvent.

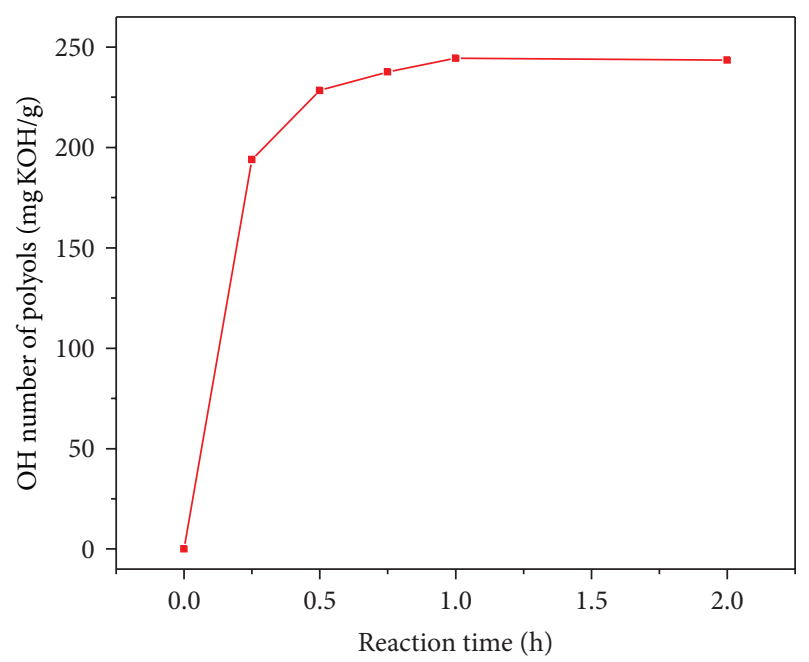

FIGURE 8: OH numbers of polyols with different reaction time.

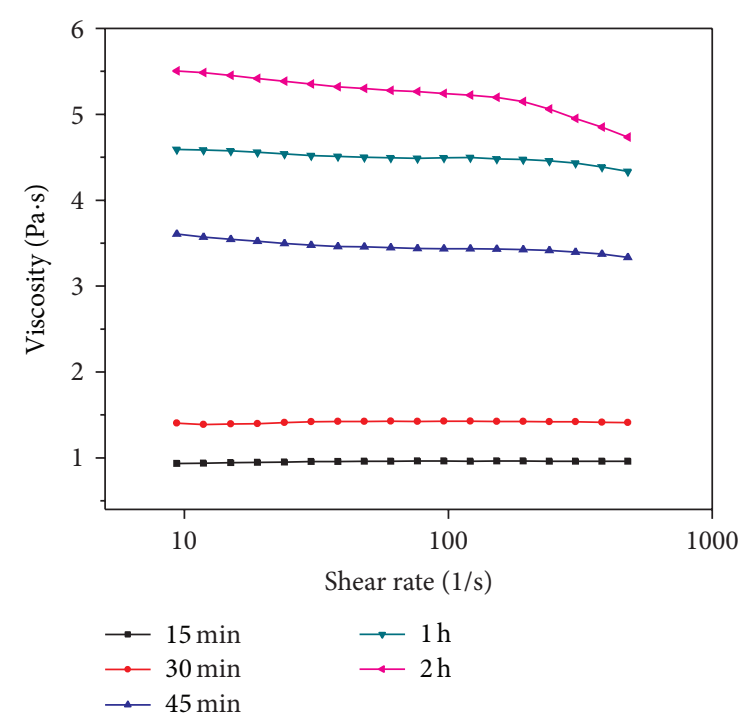

FIGURE 9: Rheological behaviors of polyols with different reaction time.

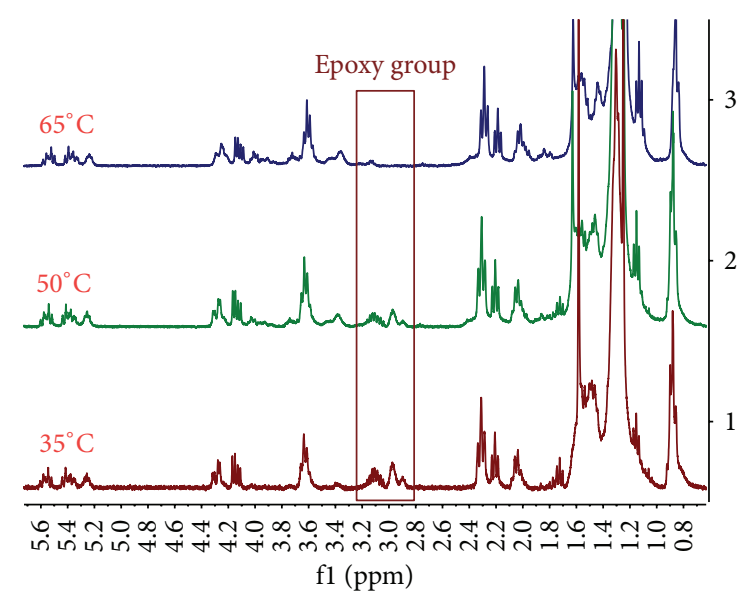

FIGURE 10: ${ }^{1} \mathrm{H}-\mathrm{NMR}$ spectrum of polyols with various reaction temperatures.

of $2 \mathrm{~h}$ was chosen to guarantee the completion. Reaction temperature of $50^{\circ} \mathrm{C}$ was selected as the benchmark. The molar ratio between COD and ESBO was varied to investigate its effect on the final polyols' structure and functionalities. ${ }^{1} \mathrm{H}-\mathrm{NMR}$ spectrums have been performed to check the degree of ring-opening of epoxy groups. Figure 12 indicates that the epoxy groups are completed ring-opened after $2 \mathrm{~h}$ reaction.

From Table 3, it is found that the $\mathrm{OH}$ numbers reasonably increase linearly with the increase of COD content while viscosity decreases. It is well known that primary hydroxyl groups are approximately 3.3-fold more reactive than secondary hydroxyl groups [26], Thus more content of COD provided more reactive primary hydroxyl groups to react with ESBO, and then more epoxy groups were ring-opened by the primary hydroxyl groups in COD, instead of being ring-opened by the newly generated secondary hydroxyl 


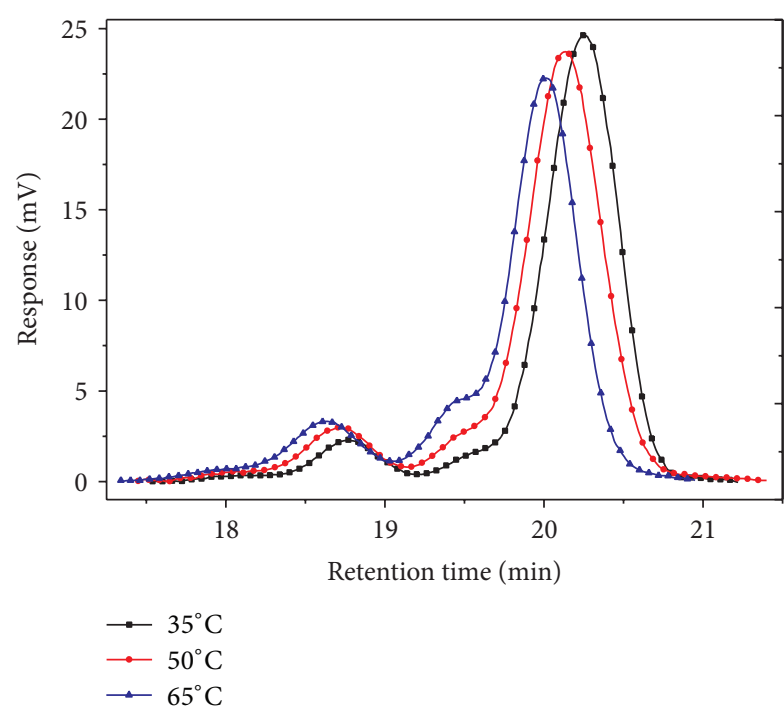

FIGURE 11: GPC plots of polyols with different reaction temperatures.

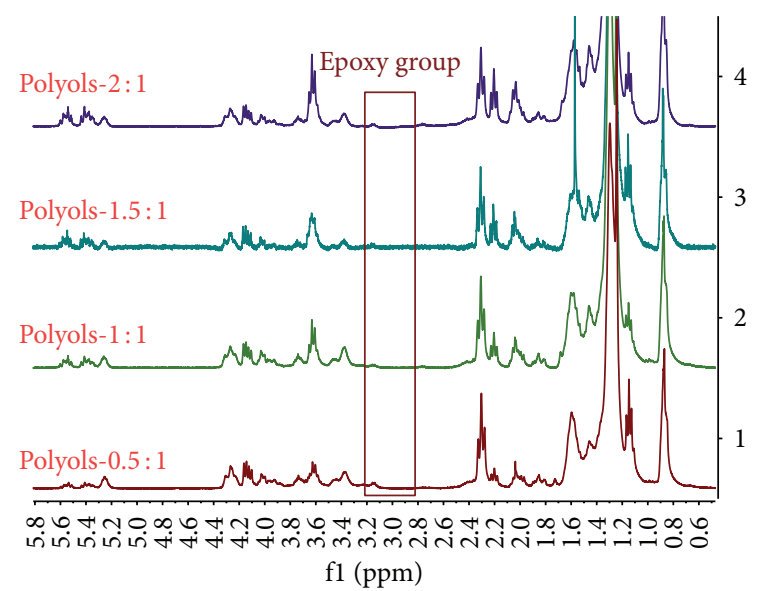

Figure 12: ${ }^{1} \mathrm{H}$-NMR spectrum of polyols with different ratios between COD and ESBO.

groups. Therefore, the cross-link densities decrease resulting in relatively lower viscosity as shown in Figure 13.

\section{Conclusions}

Biobased polyols with various functionalities were prepared from epoxidized soybean oil and castor oil-based fatty diol. NMR, FT-IR, GPC, and rheometry results showed that the functionalities, molecule weight, and viscosity of the polyols could be tailored by controlling reaction conditions, which include reaction time, reaction temperature, and molar ratios of ESBO and COD. It was found that the newly formed hydroxyl group in epoxides would also be involved in the ring-opening after the consumption of highly reactive primary hydroxyl in COD, which results in oligomerization. Moreover, as the content of COD increases, the molecular weight and viscosity of the products decrease due to the less content of ring-opening attacking sites. Increasing reaction

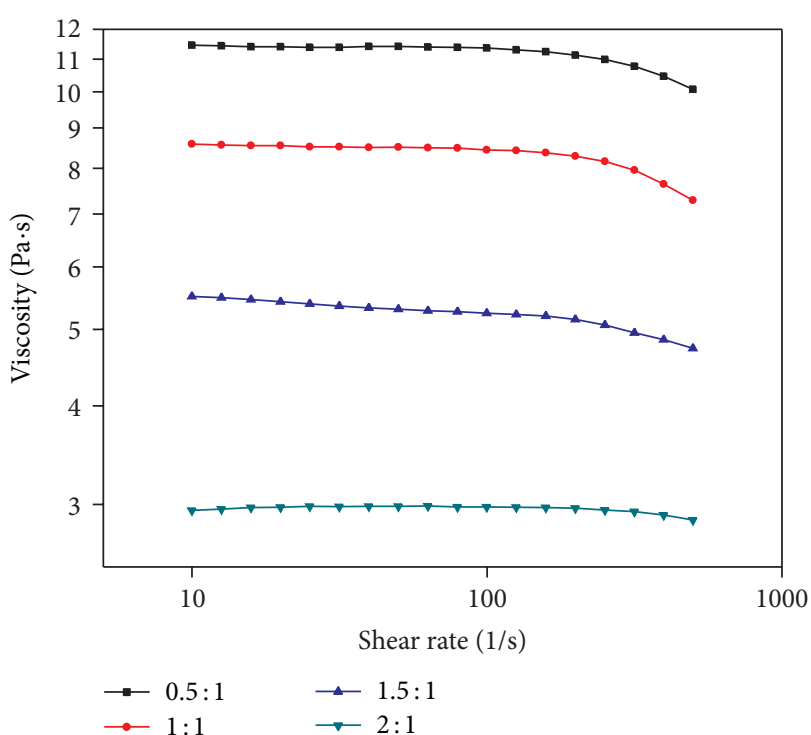

FIGURE 13: Rheological behaviors of polyols with different ratios between COD and ESBO.

temperature also favors oligomerization. Theoretically, the $\mathrm{OH}$ functionality is controlled by the content of COD. But due to presence of solvent molecule which is reactive to oxirane, hydroxyl functionality is increasing over the reaction.

\section{Conflict of Interests}

The authors declare that there is no conflict of interests regarding the publication of this paper.

\section{Acknowledgment}

The authors greatly acknowledge a project fund by the Priority Academic Program Development of Jiangsu Higher Education Institution (35061101).

\section{References}

[1] S. Corneillie and M. Smet, "PLA architectures: the role of branching," Polymer Chemistry, vol. 6, pp. 850-867, 2015.

[2] S. Laurichesse and L. Avérous, "Chemical modification of lignins: towards biobased polymers," Progress in Polymer Science, vol. 39, pp. 1266-1290, 2014.

[3] O. Faruk, A. K. Bledzki, H.-P. Fink, and M. Sain, "Progress report on natural fiber reinforced composites," Macromolecular Materials and Engineering, vol. 299, no. 1, pp. 9-26, 2014.

[4] C. K. Williams and M. A. Hillmyer, "Polymers from renewable resources: a perspective for a special issue of polymer reviews," Polymer Reviews, vol. 48, no. 1, pp. 1-10, 2008.

[5] M. R. Islam, M. D. H. Beg, and S. S. Jamari, "Development of vegetable-oil-based polymers," Journal of Applied Polymer Science, vol. 131, no. 18, pp. 40787-40799, 2014.

[6] Y. Xia and R. C. Larock, "Vegetable oil-based polymeric materials: synthesis, properties, and applications," Green Chemistry, vol. 12, no. 11, pp. 1893-1909, 2010. 
[7] C. Zhang, Y. Xia, R. Chen, S. Huh, P. A. Johnston, and M. R. Kessler, "Soy-castor oil based polyols prepared using a solventfree and catalyst-free method and polyurethanes therefrom," Green Chemistry, vol. 15, no. 6, pp. 1477-1484, 2013.

[8] T. Lebarbé, A. S. More, P. S. Sane, E. Grau, C. Alfos, and H. Cramail, "Bio-based aliphatic polyurethanes through ADMET polymerization in bulk and green solvent," Macromolecular Rapid Communications, vol. 35, no. 4, pp. 479-483, 2014.

[9] D. P. Pfister, Y. Xia, and R. C. Larock, "Recent advances in vegetable oil-based polyurethanes," ChemSusChem, vol. 4, no. 6, pp. 703-717, 2011.

[10] G. Lligadas, J. C. Ronda, M. Galiá, and V. Cádiz, "Plant oils as platform chemicals for polyurethane synthesis: current state-ofthe-art," Biomacromolecules, vol. 11, no. 11, pp. 2825-2835, 2010.

[11] C. Zhang, R. Ding, and M. R. Kessler, "Reduction of epoxidized vegetable oils: a novel method to prepare bio-based polyols for polyurethanes," Macromolecular Rapid Communications, vol. 35, no. 11, pp. 1068-1074, 2014.

[12] M. A. Alaa, K. Yusoh, and S. F. Hasany, "Synthesis and characterization of polyurethane-organoclay nanocomposites based on renewable castor oil polyols," Polymer Bulletin, vol. 72, no. 1, pp. 1-17, 2015.

[13] H. Pawlik and A. Prociak, "Influence of palm oil-based polyol on the properties of flexible polyurethane foams," Journal of Polymers and the Environment, vol. 20, no. 2, pp. 438-445, 2012.

[14] M. Desroches, M. Escouvois, R. Auvergne, S. Caillol, and B. Boutevin, "From vegetable oils to polyurethanes: synthetic routes to polyols and main industrial products," Polymer Reviews, vol. 52, no. 1, pp. 38-79, 2012.

[15] L. Maisonneuve, T. Lebarbé, E. Grau, and H. Cramail, "Structure-properties relationship of fatty acid-based thermoplastics as synthetic polymer mimics," Polymer Chemistry, vol. 4, no. 22, pp. 5472-5517, 2013.

[16] V. H. R. de Souza, S. A. Silva, L. P. Ramos, and S. F. Zawadzki, "Synthesis and characterization of polyols derived from corn oil by epoxidation and ozonolysis," Journal of the American Oil Chemists' Society, vol. 89, no. 9, pp. 1723-1731, 2012.

[17] Z. Lozada, G. J. Suppes, Y. C. Tu, and F.-H. Hsieh, "Soy-based polyols from oxirane ring opening by alcoholysis reaction," Journal of Applied Polymer Science, vol. 113, no. 4, pp. 2552-2560, 2009.

[18] A. Guo, Y. J. Cho, and Z. S. Petrovic, "Structure and properties of halogenated and nonhalogenated soy-based polyols," Journal of Polymer Science Part A: Polymer Chemistry, vol. 38, no. 21, pp. 3900-3910, 2000.

[19] Z. S. Petrovic, A. Guo, and W. Zhang, "Structure and properties of polyurethanes based on halogenated and nonhalogenated soy-polyols," Journal of Polymer Science Part A: Polymer Chemistry, vol. 38, no. 22, pp. 4062-4069, 2000.

[20] Y. Xia and R. C. Larock, "Castor oil-based thermosets with varied crosslink densities prepared by ring-opening metathesis polymerization (ROMP)," Polymer, vol. 51, no. 12, pp. 25082514, 2010.

[21] Y. S. Lu and R. C. Larock, "Soybean-oil-based waterborne polyurethane dispersions: effects of polyol functionality and hard segment content on properties," Biomacromolecules, vol. 9, no. 11, pp. 3332-3340, 2008.

[22] X. Pan and D. C. Webster, "New biobased high functionality polyols and their use in polyurethane coatings," ChemSusChem, vol. 5, no. 2, pp. 419-429, 2012.
[23] A. Adhvaryu and S. Z. Erhan, "Epoxidized soybean oil as a potential source of high-temperature lubricants," Industrial Crops and Products, vol. 15, no. 3, pp. 247-254, 2002.

[24] A. Biswas, A. Adhvaryu, S. H. Gordon, S. Z. Erhan, and J. L. Willett, "Synthesis of diethylamine-functionalized soybean oil," Journal of Agricultural and Food Chemistry, vol. 53, no. 24, pp. 9485-9490, 2005.

[25] H. V. Patel, J. P. Raval, and P. S. Patel, "Hybrid polyurethane coating systems based on renewable material," International Journal of ChemTech Research, vol. 2, no. 1, pp. 532-542, 2010.

[26] M. Ionescu, Z. S. Petrović, and X. M. Wan, "Primary hydroxyl content of soybean polyols," Journal of the American Oil Chemists' Society, vol. 85, no. 5, pp. 465-473, 2008. 

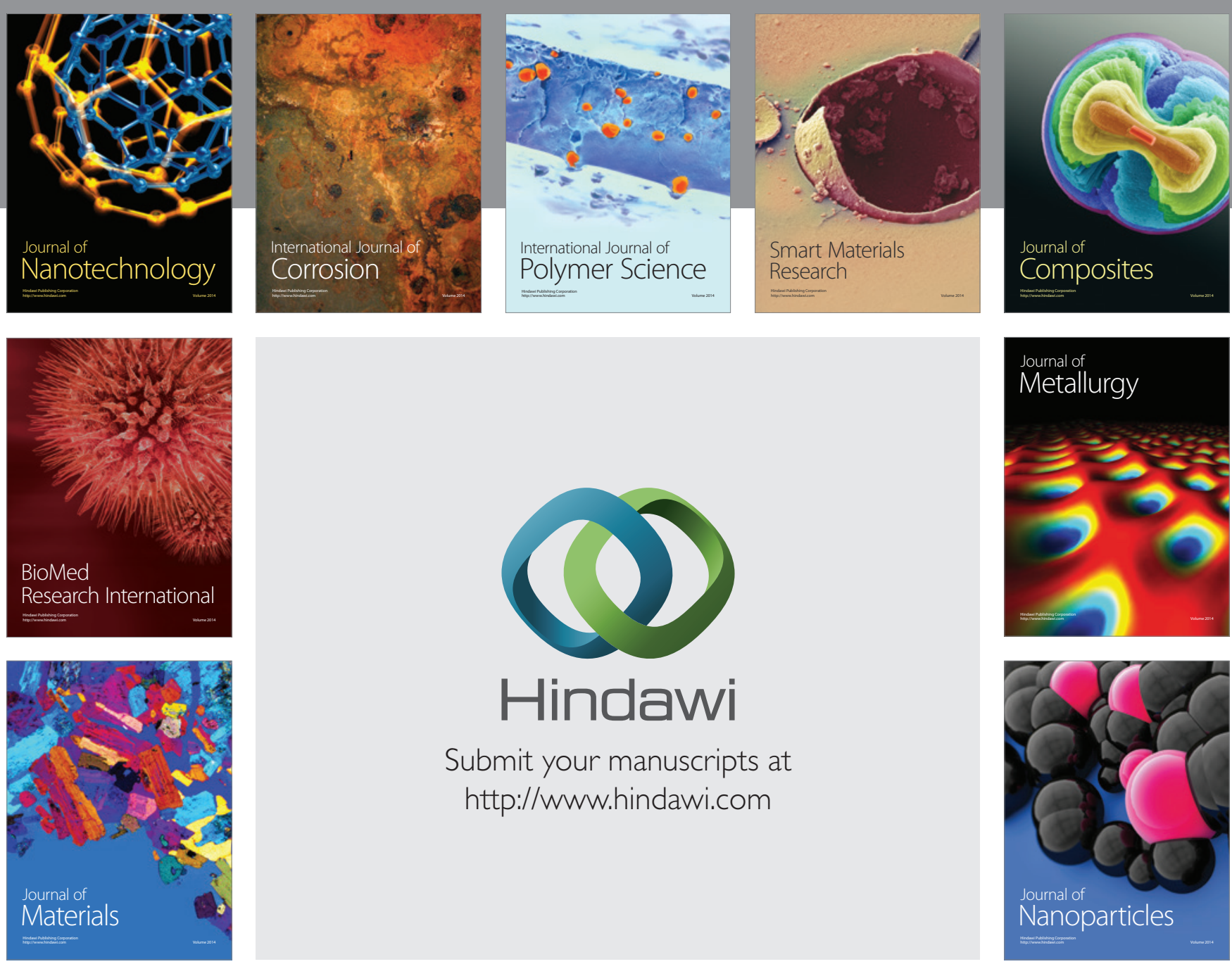

Submit your manuscripts at http://www.hindawi.com
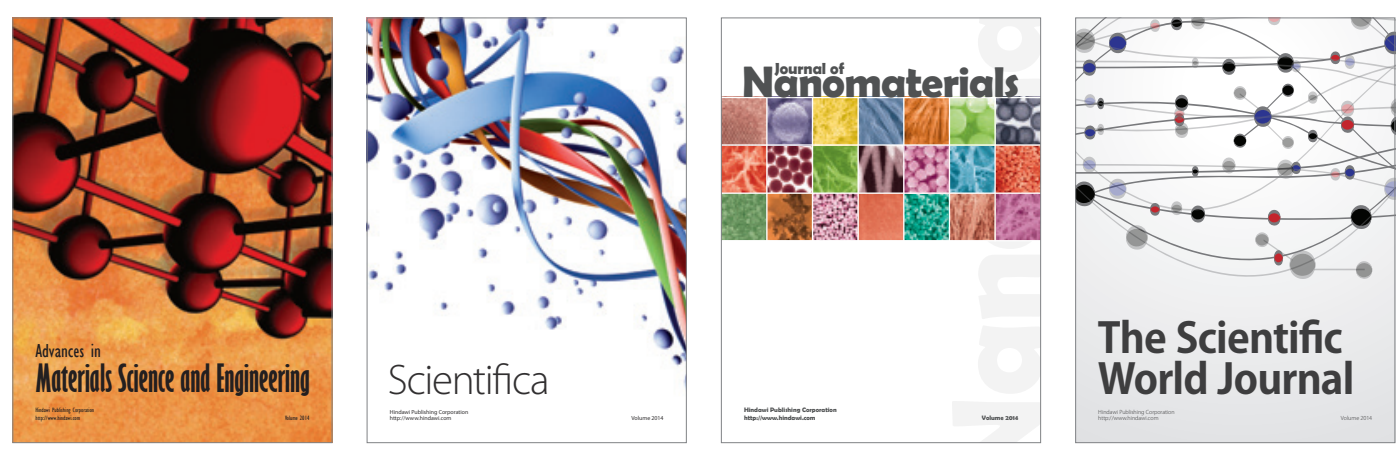

\section{The Scientific World Journal}
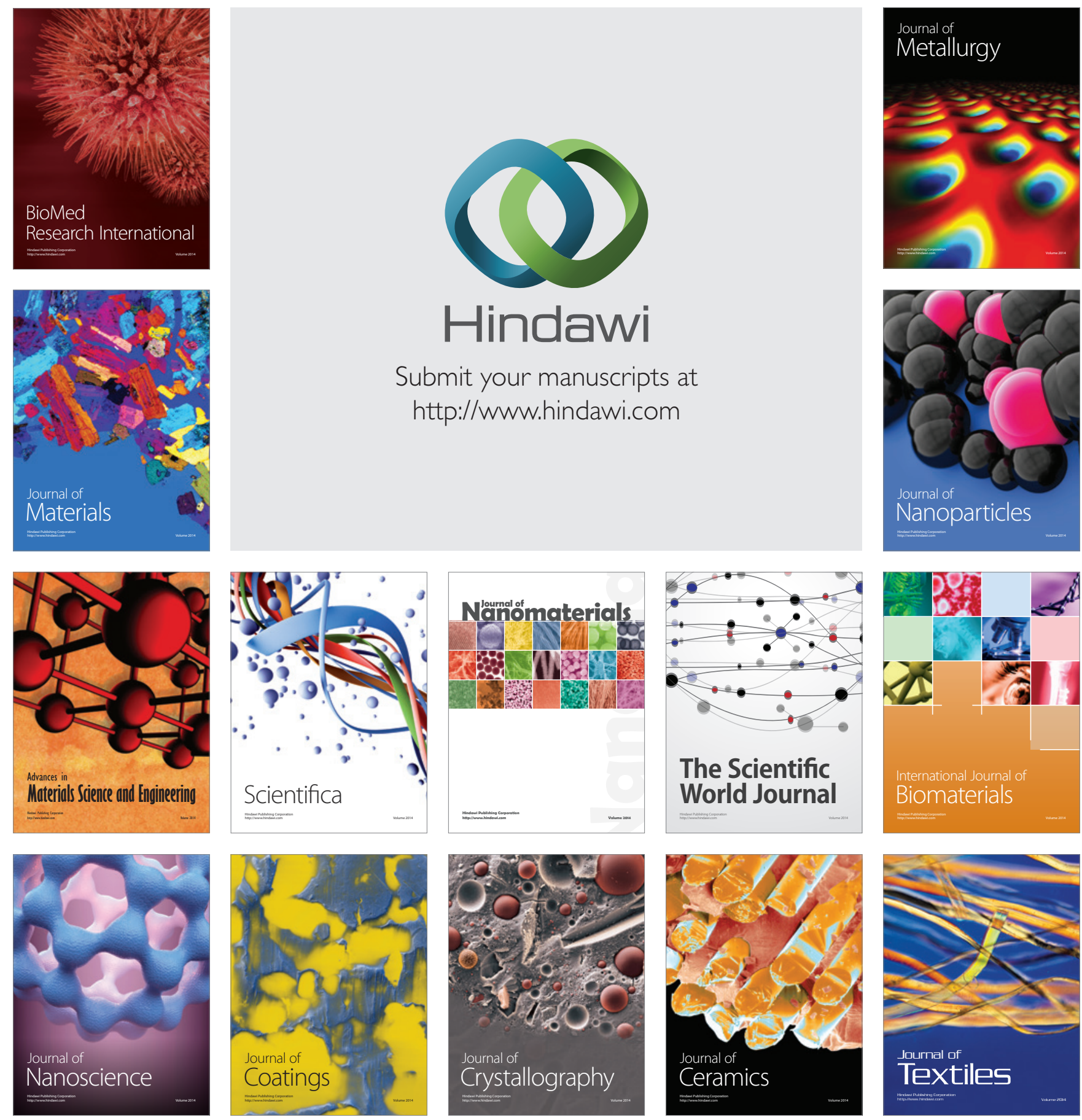